\title{
The History of Sleep Surgery
}

\author{
Kathleen Yaremchuk • Laura Garcia-Rodriguez \\ Department of Otolaryngology - Head and Neck Surgery, Henry Ford Hospital, Detroit, MI, USA
}

\begin{abstract}
Snoring and the subsequent diagnosis of obstructive sleep apnea (OSA) was a life-threatening medical condition with no available treatment until the late 20th century. An early description of OSA was provided by Charles Dickens in his 1836 novel Pickwick Papers with the description of a "fat boy" who was thought to be lazy and always falling asleep but likely displayed hypersomnolence from OSA. It was not until 1976 that lkematsu first described uvulopalatopharyngoplasty (UPPP) as an alternative surgical treatment of "snoring," with a reported cure rate of $81 \%$. The only other surgical procedure for OSA was permanent tracheostomy, but patients suffered from social stigma from the visible stoma with skin flaps and complications such as tracheal granulomas and tracheitis. UPPP was introduced in the USA as an alternative to permanent tracheostomy by Fujita in 1981. Since then, multiple surgical approaches and combinations of approaches have surfaced, with variable success rates.
\end{abstract}

(c) 2017 S. Karger AG, Basel

The diagnosis of sleep apnea stemmed from the constellation of symptoms found in the Pickwickian syndrome, a name derived from Charles Dickens' Pickwick Papers and his rotund character, Joe, who was often found to be sleeping (Fig. 1) [1]. Based on early reports of obstructive sleep apnea (OSA) in the 1950s, the disease was thought to be uncommon. Symptoms included hypersomnolence, rapid and shallow respirations, marked hypoventilation of pulmonary alveoli, and, in extreme cases, the requirement of positive-pressure ventilation [2]. Hundreds of cases were reported by the 1970s. In 1975, Carroll [3] described the differences between reports of the Pickwickian syndrome and OSA. Some patients had right-sided heart failure, respiratory acidosis, and no major abnormality in breathing, whereas others were hypersomnolent and had aberrations of respiration and sleep apneas secondary to upper airway obstruction. The latter patients had obstructions relieved by tracheostomy. In 1975, Sussman et al. [4] described 2 patients with Pickwickian syndrome with classical symptoms of periodic attacks of apnea, alveolar hypoventilation, hypersomnolence, hypertrophic tonsils, and "disturbing snoring at night."

\section{Treatment of Snoring}

Before the advent of sleep laboratories, most research focused on the treatment of snoring. In an address by Dr. Ian Robin in 1967, snoring was considered a nuisance or ridiculed, often afflicting the spouse but not the snorer [5]. Most patients did not present for evaluation since "so lit- 


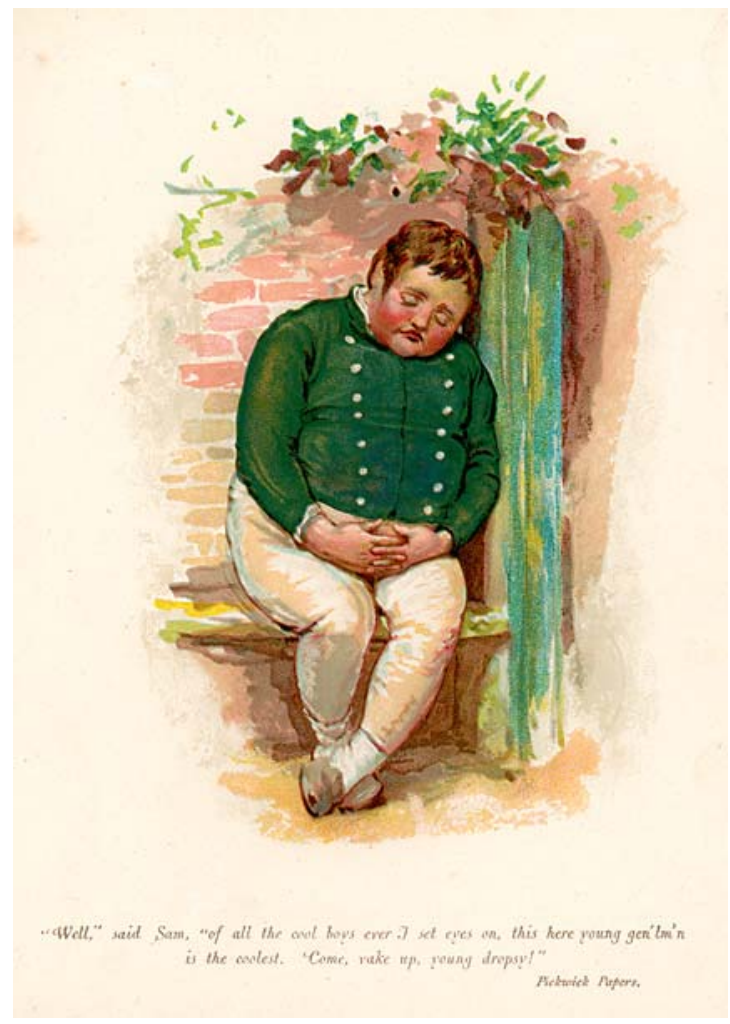

Fig. 1. Fat Joe from Pickwick Papers.

tle [was] done" [6]. In Robin's series of 200 patients, including children, he noted that the majority of the causes for snoring were adenoid hypertrophy (9\%), tonsil and adenoid hypertrophy (19\%), collapsed nasal ala (23\%), deviated septum (25\%), and hypertrophic turbinates. Snoring significantly improved with surgical intervention [6].

The sounds of snoring were speculated to be due to vibrations from the epiglottis, velum, cheeks, or nostrils, and were later confirmed with a nasopharyngoscope. Treatment was advocated but it was also considered that "isolation may be the only effective measure" for snoring [7]. Even in the 1970s, divorce was justified as a solution to snoring $[8,9]$. Surgery was morbid and some chose alternative methods for snoring cessation, including sewing a marble to the upper part of a nightshirt as a remind- er not to sleep supine [10] or using a cervical collar to maintain an extended neck position [9].

Continuous positive airway pressure (CPAP) was first used to treat pulmonary disease, such as pulmonary edema, but with endotracheal administration [11]. In 1975, Allen et al. [12] successfully introduced the application of a nontraumatic facemask for use with CPAP in newborns as a way to avoid endotracheal intubation. Treatment of OSA with CPAP was introduced by Sullivan et al. [13] in 1981, resulting in complete cessation of upper airway obstruction and a restful night's sleep. Since the introduction of CPAP, not everyone has gained access to the equipment and some find it cumbersome, so alternative treatment methods have been sought.

\section{Surgical Procedures}

In the 1950s, procedures for snoring included the resection of soft palate triangles just paramedian of the uvula, a concept invented by Schwartz [14]. This appeared to be the beginning of multiple procedures that used the same concept for reconstruction of the soft palate.

Amputation of the uvula was introduced in the 1960 s, but only changed the pitch and not the occurrence of snoring [6]. Uvulectomy had been a tradition in Morocco for hundreds of years. Undertaken during infancy with a wooden spatula or a reed fork and a falciform bistoury, uvulectomy was meant to facilitate breastfeeding and speech. It was associated with the atrophy of regional lymphoid tissue and thus speculated that these infants were less prone to otitis media and adenotonsillitis [15]. Uvulectomy was not endemic to Morocco, but was widely practiced in African tribes. The procedure was performed by tribal healers based on the belief that it was preventative for throat and chest infections [16].

In the 1970s, tracheostomy became the standard treatment for Pickwickian syndrome, OSA, severe daytime somnolence with associated hy- 
pertension, and cardiac electrophysiologic changes. Most advocated performing a permanent stoma $[17,18]$. However, in the 2 patients with Pickwickian syndrome studied by Sussman et al. [4], tonsillectomy ceased their symptoms with normalization of arterial blood gases 3 years postoperatively. Permanent tracheostomy had its complications of reported tracheal granulomas, tracheitis, and patients suffering social stigma from the permanent skin flap [19].

The Japanese practiced palatopharyngoplasties for many years before the procedure became popular in the USA [20]. Ikematsu [21] first proposed uvulopalatopharyngoplasty (UPPP) in 1964 in those afflicted with snoring (Fig. 2). His interest was first sparked in 1954 when a woman was divorced due to her loud snoring [22]. He advocated a morphological evaluation of the soft palate, uvula, pharynx, and the presence of snoring. Cephalometric analyses were performed to identify troublesome areas followed by a description of the surgical procedure and postoperative instructions. Treatment with surgery resulted in an $81 \%$ improvement of snoring [21].

Introduced in the USA by Fujita et al. [23] in 1981, UPPP was performed on 12 patients with OSA. Eight showed an improvement on polysomnogram and 9 had an improvement of subjective symptoms. The concept of the surgery was to enlarge the potential airspace in the oropharynx and cause stiffening of oropharyngeal tissues to avoid collapse and turbulent airflow. UPPP showed mixed results on polysomnograms, with some demonstrating up to $50 \%$ response rates with a variability in complications [24]. Patients would claim a significant subjective improvement in their symptoms despite objective changes on polysomnogram (Fig. 3).

In 1983, Cotton [25] presented the idea that UPPP should be used in conjunction with tracheostomy in patients with life-threating sleep apnea. That same year, Simmons et al. [26] presented the idea that the resection of superfluous palate could cure habitual snoring and treat at least $50 \%$ of

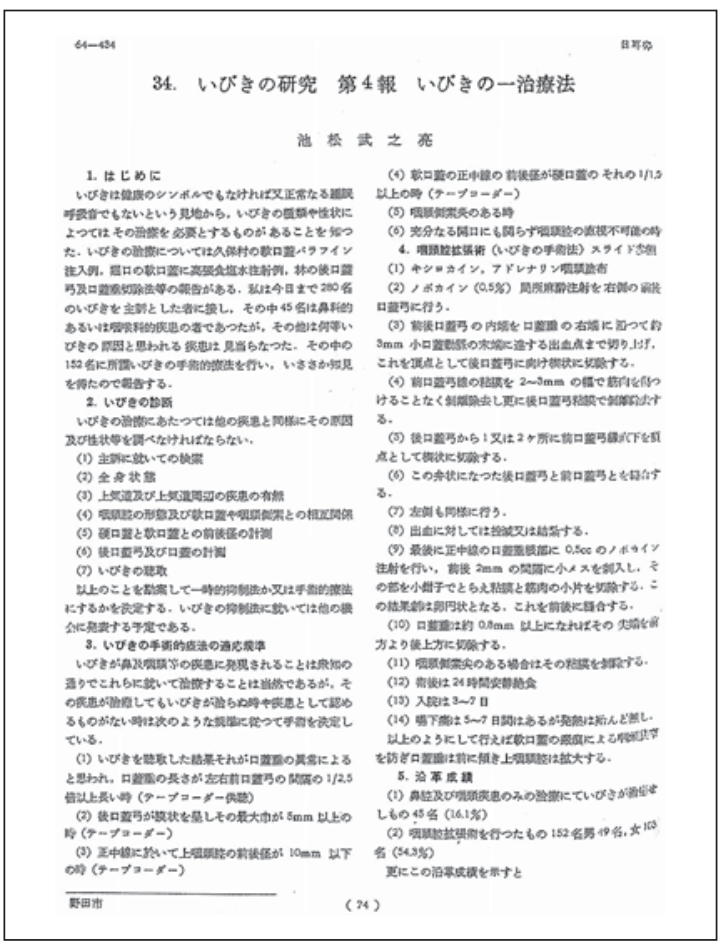

Fig. 2. Ikematsu's proposal for uvulopalatopharyngoplasty in those afflicted with snoring [21].

OSA patients via palatopharyngoplasty. They warned of using the procedure in the morbidly obese or those with hypoventilation syndrome. The procedure was slightly different in that the uvula was simply excised, whereas it was repositioned in Fujita's approach. Simmons removed only as much soft palate as possible whilst avoiding velopharyngeal insufficiency (Fig. 4).

The earliest report of UPPP in a child was made in 1988, since most children are treated with adenotonsillectomy. The procedure was completed successfully in a 3-year-old with a large uvula and redundant soft palate, with a full resolution of symptoms at the 1-year follow-up [27].

Two phases of treatment have been suggested based on the complexity of OSA. Phase I, the conservative approach, includes UPPP, mandibular osteotomy with genioglossus advancement, hy- 
Fig. 3. Uvulopalatopharyngoplasty as described by Fujita et al. [23; with permission from SAGE Publications, Inc.] in 1981.
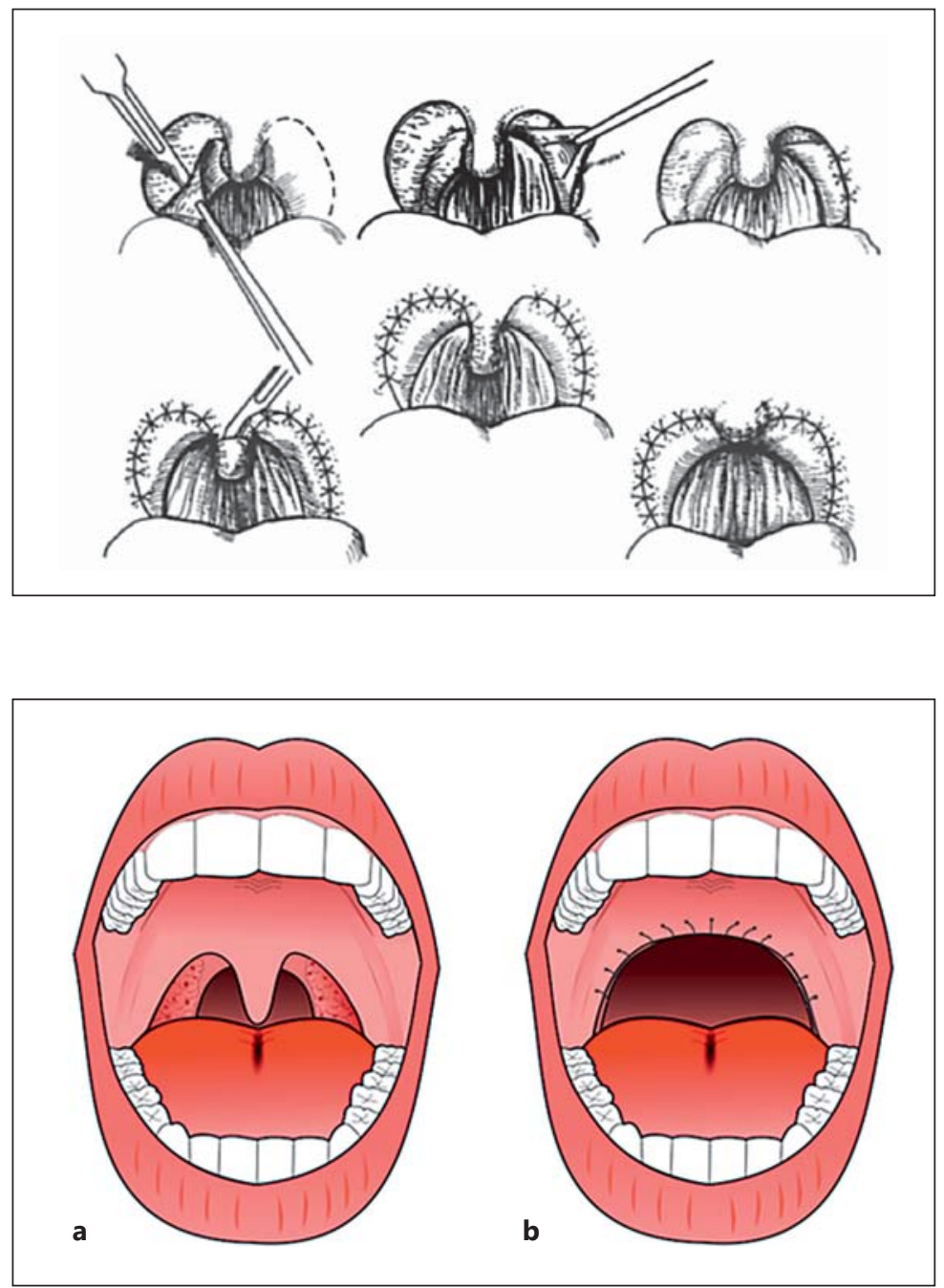

Fig. 4. Palatopharyngoplasty as described by Simmons et al. [25] in 1983. Preoperative (a) and original UPPP (b). The image is courtesy of Dr. Camacho (DrCamachoENT) and available at https://commons.wikimedia.org/wiki/File:UPPP._4_figures..png. sisted uvulopalatoplasty. Intended to "vaporize" vibrating tissues of the tonsillar pillars and soft palate, the procedure can be performed in 1 or more sessions as needed for the required results in an office setting. It was deemed "simple, bloodless, and painless," under the use of local anesthesia. However, the procedure was promoted for habitual snorers [30].

An extension of UPPP was presented by O'Leary and Millman [24] in 1991, in which they advocated resection of the palatopharyn- 
geus and palatoglossus, increasing the area of the posterior oropharynx. Other procedures have been modeled after the principle of UPPP, such as snare uvulopalatoplasty, introduced by Weingarten [31] in 1991 for the treatment of habitual snoring. This procedure was meant to be performed in the clinic with local anesthesia using a snare.

\section{Conclusion}

Despite all of the advances made during these last few decades for OSA surgery, no single treatment is successful for all patients. As Guilleminault [32] said in 1998, "to offer only one of these [treatments] or to limit oneself to a single therapeutic approach is a long-term disservice."

\section{References}

1 Kryger MH: Fat, sleep, and Charles Dickens: literary and medical contributions to the understanding of sleep apnea. Clin Chest Med 1985;6:555-562.

2 Pickwickian syndrome. Br Med J 1958;2: 964.

3 Carroll D: Pickwickian syndrome, 20 years later. Trans Am Clin Climatol Assoc 1975;86:112-127.

4 Sussman D, Podoshin L, Alroy G: The Pickwickian syndrome with hypertrophy of tonsils: a re-appraisal. Laryngoscope 1975;85:565-569.

5 Snoring husbands. Chicago Tribune, July 16, 1968, p 14. http://archives.chicagotribune.com/1968/07/16/page/38/ article/comic-5-no-title.

6 Robin I: Snoring [abridged]. Proc R Soc Lond 1968;61:575-582.

7 Snoring. Can Med Assoc J 1948;59:383384.

8 Seiler ER: The incidence of snoring as a sleep problem in parents. J R Coll Gen Pract 1970;19:247.

9 Broomes EL: New thoughts on snoring prevention. J Natl Med Assoc 1982;74: 1139-1140.

10 Help a snorer. JAMA 1981;245:1729-1730.

11 Cheney FW Jr, Martin WE: Effects of continuous positive-pressure ventilation on gas exchange in acute pulmonary edema. J Appl Physiol 1971;30:378-381.

12 Allen LP, Blake AM, Durbin GM, Ingram D, Reynolds EO, Wimberley PD: Continuous positive airway pressure and mechanical ventilation by facemask in newborn infants. Br Med J 1975;4: 137-139.
13 Sullivan CE, Issa FG, Berthon-Jones M, Eves L: Reversal of obstructive sleep apnoea by continuous positive airway pressure applied through the nares. Lancet (London) 1981;1:862-865.

14 Heinberg CJ: A surgical procedure for the relief of snoring. Eye Ear Nose Throat Mon 1955;34:389.

15 Apffel CA: Uvulectomy, ethnic mutilation of prophylactic surgery: an oriental tale. JAMA 1965;193:164-165.

16 Sawe HR, Mfinanga JA, Ringo FH, Mwafongo V, Reynolds TA, Runyon MS: Morbidity and mortality following traditional uvulectomy among children presenting to the Muhimbili National Hospital Emergency Department in Dar es Salaam, Tanzania. Emerg Med Int 2015; 2015:108247.

17 Weitzman ED, Pollack CP, Borowiecki $\mathrm{B}$ : Hypersomnia-sleep apnea due to micrognathia: reversal by tracheoplasty. Arch Neurol 1978;35:392-395.

18 Fee WE Jr, Ward PH: Permanent tracheostomy: a new surgical technique. Ann Otol Rhinol Laryngol 1977;86:635638.

19 Conway WA, Victor LD, Magilligan DJ Jr, Fujita S, Zorick FJ, Roth T: Adverse effects of tracheostomy for sleep apnea. JAMA 1981;246:347-350.

20 Simmons FB: Otolaryngology/head and neck surgery - important advances in clinical medicine: snoring. West J Med 1982;137:228.

21 Ikematsu T: Study of snoring: therapy [in Japanese]. J Jpn Otol Rhinol Laryngol Soc 1964;64:434-435.
Kathleen Yaremchuk, MD

Department of Otolaryngology - Head and Neck Surgery

Henry Ford Hospital, 2799 West Grand Boulevard

Detroit, Ml 48202 (USA)

E-Mail kyaremc1@hfhs.org
22 Ikematsu A. YU, Niho M: The Ikematsu system for the diagnosis of snoring: a review of 39 years of clinical studies; in Togawa K, Katayama S, Hishikawa Y, Ohta Y, Horie T (eds): Sleep Apnea and Rhonchopathy. Basel, Karger, 1993.

23 Fujita S, Conway W, Zorick F, Roth T: Surgical correction of anatomic abnormalities in obstructive sleep apnea syndrome: uvulopalatopharyngoplasty. Otolaryngol Head Neck Surg 1981;89: 923-934.

24 O’Leary MJ, Millman RP: Technical modifications of uvulopalatopharyngoplasty: the role of the palatopharyngeus. Laryngoscope 1991;101:1332-1335.

25 Cotton RT: Uvulopalatopharyngoplasty. Arch Otolaryngol 1983;109:502.

26 Simmons FB, Guilleminault C, Silvestri R: Snoring, and some obstructive sleep apnea, can be cured by oropharyngeal surgery. Arch Otolaryngol 1983;109: 503-507.

27 Abdu MH, Feghali JG: Uvulopalatopharyngoplasty in a child with obstructive sleep apnea: a case report. J Laryngol Otol 1988;102:546-548.

28 Riley RW, Powell NB, Guilleminault C: Obstructive sleep apnea syndrome: a surgical protocol for dynamic upper airway reconstruction. J Oral Maxillofac Surg 1993;51:742-747; discussion 748-749.

29 Friedman M: Sleep Apnea and Snoring. Beijing, Elsevier, 2009.

30 Kamami YV: Laser $\mathrm{CO}_{2}$ for snoring: preliminary results. Acta Otorhinolaryngol Belg 1990;44:451-456.

31 Weingarten C: Snare uvulopalatoplasty. Laryngoscope 1995;105:1033-1036.

32 Guilleminault C: Treatment of obstructive sleep apnea syndrome: a personal view based upon evaluation of over 4,000 patients. Schweiz Med Wochenschr 1988;118:1342-1347. 